\title{
Editorial: Remote and Proximal Sensing of Grasslands
}

\author{
Peter Krzystek $k^{1,2} \cdot$ Georg Bareth ${ }^{1,3}$
}

(c) The Author(s) 2020

Even a short glance at the Web of Science clearly shows that research interest in grassland and remote sensing for monitoring purposes has increased significantly since 2010. Furthermore, research activities in using Unmanned Aerial Vehicles (UAVs) for grassland monitoring have risen almost exponentially since 2015 , with first studies using remotely controlled fixed wing or helicopter UAVs dating back to the 1990s. The answers to why grasslands have become of more interest are manifold. One reason is their diversity, ranging from natural grassland, over extensively used pastures and meadows to very intensively managed systems. Ecosystems connected with prairies, pampas, steppes, savannahs, rangelands, alpine pastures, silvo-pastoral systems, and many more characterize grasslands diversity and their global presence. Estimates show that $30-40 \%$ of the terrestrial land masses are covered by these grassland ecosystems. Another reason is their importance in the context of global and climate change. Soils are the largest carbon stock and the significance of grasslands in the global carbon cycle and their role as a carbon sink are well known. Furthermore, managed grasslands are an important food supplier and play an essential role in the agribusiness when it comes to producing meat, milk, cheese, wool, etc.

Considering this background, the DGPF Working Group "Remote Sensing Applications for Forestry and Agriculture" decided to initiate special sessions on remote and proximal

Georg Bareth

g.bareth@uni-koeln.de

Peter Krzystek

peter.krzystek@hm.edu

1 DGPF Working Group "Remote Sensing Applications for Forestry and Agriculture", Cologne, Germany

2 Department of Geoinformatics, University of Applied Sciences Munich, 80333 Munich, Germany

3 University of Cologne, Institute of Geography, GIS \& RS Group, 50923 Cologne, Germany sensing of grasslands at the annual DGPF conference in Stuttgart in March 2020 (Stilla 2020). At the same time, the Working Group announced in 2019 a call for this special issue on the same topic. The four papers of our special issue, the presentations at the DGPF 2020 conference (2020), and the two papers of the conference proceedings clearly show the broad topics when it comes to remote sensing of grasslands. The applied sensors of the studies range from satellite to UAV sensors and include proximal sensing for grassland research.

In the conference proceedings, Schaumberger and Adelwöhrer (2020) present an impressive data management system, the SpectroAnalyst, for handling spectral experiment plot data acquired with field spectroradiometers. Wachendorf et al. (2020) applied the Cubert Firefly, a hyperspectral UAV-mounted imaging sensor, to estimate forage quality and invasive species in species-rich grasslands. The authors found high $R^{2}$ in forage quality estimation and established an analysis workflow to map invasive species.

In this special issue, two papers present Sentinel-2 data analysis to estimate LAI for grasslands. The first one is a study by Schwieder et al. (2020, https://doi.org/10.1007/ s41064-020-00120-1) that show how Sentinel-2 data can be applied to map grassland parameters such as biomass and LAI. Similar results for LAI are presented by Klingler et al. (2020, https://doi.org/10.1007/s41064-020-00119-8) who investigated different indirect and direct methods of LAI retrieval. Both studies evaluated their Sentinel-2 data analysis using comprehensive field measurements. Wijesingha et al. (2020, https://doi.org/10.1007/s41064-020-00121 -0) presented a detailed study on mapping invasive species in semi-natural grasslands using an object-based image analysis approach. In that study, UAV-derived RGB and thermal data in ultra-high resolution were acquired and analyzed. Finally, Lussem et al. (2020, https://doi.org/10.1007/ s41064-020-00117-w) use a 3-year data set to investigate the potential of low-cost UAVs and RGB data acquisition for forage mass monitoring.

In general, promising remote-sensing approaches to monitoring grasslands are (1) stereo-photogrammetry to 
derive precise sward height and growth, (2) multi- and hyperspectral data analysis for forage quality and quantity, and (3) machine learning as well as combined spectral and structural data analysis. However, the spatial and temporal heterogeneity of grasslands when establishing robust estimators for monitoring purposes remains research challenges. The 2021 virtual conference of the European Grasslands Federation (EFG) picks up on the increasing importance of this topic with its title: "Sensing-New insights into grassland science and practice" (https://www.uni-kasse 1.de/go/egf2021)."

And at the DGPF 2021 annual conference in March 2021, we will again organize conference sessions on remote sensing of forestry, crops, and grasslands. Updates will be announced on the DGPF website (https://www.dgpf.de/ con/).

\section{Peter Krzystek and Georg B AReth}

Funding Open Access funding enabled and organized by Projekt DEAL.
Open Access This article is licensed under a Creative Commons Attribution 4.0 International License, which permits use, sharing, adaptation, distribution and reproduction in any medium or format, as long as you give appropriate credit to the original author(s) and the source, provide a link to the Creative Commons licence, and indicate if changes were made. The images or other third party material in this article are included in the article's Creative Commons licence, unless indicated otherwise in a credit line to the material. If material is not included in the article's Creative Commons licence and your intended use is not permitted by statutory regulation or exceeds the permitted use, you will need to obtain permission directly from the copyright holder. To view a copy of this licence, visit http://creativecommons.org/licenses/by/4.0/.

\section{References}

Stilla U (2020) https://dgpf.de/src/tagung/jt2020/proceedings/proce edings/sessions.html

Schaumberger A, Adelwöhrer M (2020) https://dgpf.de/src/tagung/ jt2020/proceedings/proceedings/papers/21_DGPF2020_Schau mberger_Adelwoehrer.pdf

Wachendorf M, Astor T, Wijesingha J (2020) https://dgpf.de/src/tagun g/jt2020/proceedings/proceedings/papers/20_DGPF2020_Wache ndorf_et_al.pdf 